\title{
Verdad y verosimilitud en la poética: Paz y Aristóteles
}

\author{
Josemaría Camacho \\ Universidad Panamericana
}

\begin{abstract}
The main objective of this work is to discover the close relation that Paz's opinion keeps with Aristotle's when they talk about the reaches of poetry. First, I try to explain the various meanings of the concept 'truth' in Aristotle's work, in order to understand the precise way that he means when refering to poetry. Then, I try to compare both opinions grounded in the similar conceptions about the necesity of verosimilitude they think poetry must observe. Altough they both predicate this necesity to poetry, they have diferent reasons to do it. I conclude this work explaining those reasons.
\end{abstract}

\section{Aristóteles}

Es necesario comprender, en primera instancia, que la verdad en la visión aristotélica se puede desdoblar en por lo menos dos registros diferentes. El primero se refiere a la dimensión lógica. Esto es, que se trata de la verdad y la falsedad que se dan propiamente en el juicio. El segundo se refiere a una verdad ontológica, que responde a la existencia del objeto del cual se predica. El análisis sobre la verdad de la poesía 0 , en general, del arte imitativo, pues, tendrá estas dos vertientes respectivas.

Pero antes de comenzar el análisis directo, es necesario hablar sobre la esencia del arte en la perspectiva de la Poética. Y hemos de recordar, en un principio, que la poesía se encuentra encasillada en el orden de las cosas artificiales, en contraposición con las cosas naturales. Como ser artificial, conlleva una desvinculación de las cuatro causas aristotélicas por intervención de la creatividad humana. 
En efecto, la causa material entendida como ímpetu o potencialidad hacia una forma, estará dirigida en el ser artificial hacia una forma no natural, sino resultado de la deliberación de un agente externo. Las causas formal, eficiente y final, por tanto, también estarán manipuladas por un agente externo, de tal modo que no continuarán siendo las que naturalmente tenia el objeto modificado. Los entes artificiales son fruto de una actividad poiética o transformadora y resultado de la aplicación de una tejné o técnica artística. La caracteristica esencial de la obra artificial es, además de la desvinculación de las cuatro causas naturales, el hecho de que se encuentra por encima de la simple experiencia, dado que el arte versa sobre lo universal mientras que la experiencia trata de lo particular.

El ser se dice de muchas maneras ${ }^{1}$, y en todas esas maneras de ser y de no ser, la poesía siempre ocupa un lugar intermedio. Esto es, si el ser es la sustancia y el no-ser es la categoria no substancial o accidente, la poesía está en un término medio puesto que en sí misma, como fruto de la actividad poiética, es substancial y susceptible de cambiar en sus accidentes. No obstante, parece no tener la misma substancialidad que aquello que es su modelo. Ahora bien, si el ser es el acto y el no-ser es la potencia, la poesía, que trata sobre algo posible, es algún tipo de potencia, pero no es el contrario más alejado del acto, el cual sería aquello que es imposible. Por otra parte, si hablamos del ser como ente veritativo, parece que la poesía no está en condiciones para ser juzgada bajo este aspecto, puesto que no habla sobre lo fáctico sino sobre lo posible, y no se puede comparar con la realidad para emitir un juicio sobre su verdad o su falsedad.

Pero, ¿qué es la verdad en el contexto aristotélico? Podemos hablar, como se ha mencionado, de un doble registro. Comencemos con el lógico: es bien sabido que en la lógica aristotélica hay variados elementos. Están el nombre y el verbo, principalmente. La verdad en el sentido lógico se da en la unión de estos dos elementos, esto es, en la predicación. Y esta verdad es propia de la mente

${ }^{1}$ Cf. ARISTóteles: Metafisica 1028a10-13. 
cuando, para expresarse, une o separa términos a través de un verbo. La verdad corresponderá, pues, al enunciado que una algún predicado con un sujeto al que le corresponda. Y la falsedad, cuando no corresponda esa unión. El sólo nombre o el sólo predicado no están sujetos a verdad o a falsedad. ${ }^{2}$

Esta idea se encuentra corroborada en un texto de la Metafisica, que afirma que este tipo de verdad, el lógico, no está en las cosas: "no están lo falso y lo verdadero en las cosas, como si lo bueno fuese verdadero y lo malo falso, sino en el pensamiento". ${ }^{3} \mathrm{Y}$ un poco más adelante, antes de terminar el libro sexto, recalca que este modo de ser, según el ente veritativo, no es el modo en que las cosas son en si: " $y$, puesto que la complexión y la separación se dan en el pensamiento, pero no en las cosas, el ente en este sentido es un ente diferente a los entes en sentido propio (...)". ${ }^{4}$

Una vez establecido que la verdad lógica se halla en la predicación o aseveración, o dicho propiamente, en el juicio, podriamos pensar que los elementos que conforman la poesía, al ser enunciados 0 juicios, son susceptibles de verdad y de falsedad. No obstante, existe un texto del tratado acerca de la interpretación o Peri Hermeneias que vale la pena transcribir, puesto que puede arrojar luz al respecto:

Todo enunciado es significativo, pero no como un instrumento natural, sino por convención, como ya se ha dicho; ahora bien, no todo enunciado es asertivo, sino sólo aquel en que se da la verdad o la falsedad: y no en todos se da, por ejemplo, la plegaria es un enunciado, pero no es verdadero ni falso. Dejemos, pues, de lado esos otros - ya que su examen es más propio de la Retórica o la Poética-, ya que el objeto del presente estudio es el enunciado asertivo. $^{5}$

\footnotetext{
2 Cl. ARIstóteles: Peri Hermeneias, 16a13-18.

3 ARISTÓTELEs: Metafisica, 1027b 25-27.

${ }^{4}$ Aristóteles: Metafisica, 1027b 29-31.

${ }^{5}$ ARISTÓTEles: Peri Hermeneias, 17a 1-8.
} 
En concreto, Aristóteles se refiere, al hablar de los enunciados que no son ni verdaderos ni falsos, a los enunciados no asertivos. Dentro de esta categoría podemos incluir, licenciándonos con la aclaración que el mismo Aristóteles hace al final de la cita anterior, a los enunciados de tipo poético. Esto es tanto como decir que, en un sentido lógico, los enunciados que conforman la obra poética no son verdaderos, pero, sobre todo, que no son tampoco falsos. ${ }^{6}$

No obstante, es necesario salir al paso de una posible objeción: la poesía, se ha dicho, no presenta hechos sino ficciones, cosas que no han sucedido. $\mathrm{Y}$ estas creaciones representadas por la poesía no son reales, por lo que no importa siquiera si son verdaderas o no. A este respecto, Aristóteles podría decir que la poesía no habla de lo real, sino de una realidad superior, que no está sujeta a lo particular ni a lo accidental, que no cambia. La poesía habla de lo que 'debería ser', no de lo que 'es'. La poesía en la visión de Aristóteles, dice Butcher, no se ocupa de los hechos, sino de aquello que trasciende a los hechos. Representa cosas que no son y que nunca pueden ser en la experiencia actual. Nos da, sin embargo, el 'debe ser', una forma que se corresponde con la idea verdadera.?

Hay, sin embargo, otra verdad que no se da en el juicio, es decir, que no es de carácter lógico. Esta es la comúnmente llamada verdad ontológica. La verdad lógica, como veiamos, se da en la mente de quien enjuicia una realidad, en el fuero interno de quien une o separa mediante el lenguaje un nombre y un predicado y sólo cuando hay una comparación con la realidad.

"Puesto que ente y no-ente se dicen, en un sentido, según las figuras de las categorías, en otro, según la potencia o el acto de estas categorías o según sus contrarios, y, en otro [que es el más propio], verdadero o falso". ${ }^{8}$ Derivado de este texto, podemos decir que hay otro sentido de verdad en Aristóteles que va más allá del sentido

${ }^{6}$ Cf. Wladyslaw Tatarkiewicz: Historia de seis ideas: Arte, Belleza, Forma, Creatividad, Mimesis, Experiencia estética, Madrid: Tecnos 1997. pp. 338-339.

${ }^{7}$ Cf. S.H. BUTCHER: Aristotle's Theory of Fine Art, Nueva York: Dover 1951, p. 168.

${ }^{8}$ ARISTÓTELES: Metafisica. 1051a 34-1051b 2. 
lógico y que podría responder como el sentido más propio de ser que se menciona aquí. El ser es lo verdadero, esto es, que todo aquello que es, por el simple hecho de ser, es verdadero, en contraposición con el no ser, que es lo falso. Desde esta perspectiva, podemos decir que la obra artística es un ser, aunque no natural sino artificial. Concluimos con esto que, dado que el resultado de la actividad poiética existe, es por ello verdadero en cuanto tal. En este sentido de verdad parece no haber duda en cuanto a la veracidad de la obra artística.

Debemos decir, no obstante, que la entidad o el lugar que ocupa la obra artística en la escala de seres es relativa. Si bien es cierto que existe y que, por tanto, ocupa realmente un lugar en la gradación ontológica, escapándose por completo del no-ser absoluto (el cual, en sentido estricto, es lo único que no existe), su lugar está por debajo del lugar que ocupa el modelo del cual ha sido tomada la obra. El arte poético procede por mimesis o reproducción imitativa, y esto implica que existe un modelo del cual toma forma la obra artística. Este modelo es, en el caso de la tragedia como ejemplo mejor de la obra poética, la acción humana. Por tanto, el modelo tendrá más entidad que el resultado de su imitación.

A partir de la idea de que el artista crea de acuerdo a un modelo que es, en fin, un 'crear de acuerdo a una idea', 9 podemos encontrar otro matiz del concepto de verdad que sea aplicable a la poética. En efecto, la obra puede ser considerada como verdadera en tanto que se asemeje a la idea que funge como modelo para el artista.

En el caso concreto de la Poética de Aristóteles el modelo no es un ente natural sino la acción humana, o mejor dicho, una idea fruto de la especulación sobre la acción humana pero considerada como universal. Esto quiere decir que, dado que el artista en la perspectiva aristotélica puede narrar las cosas de una manera mejor a como de hecho sucedieron, y dado que habla de lo que podria haber sucedido y puede mejorar lo que realmente sucedió, entonces este mejoramiento no se da al plasmar la idea del artista en una obra, sino

${ }^{9}$ Cf. S.H. Butcher: Aristotle's Theory..., p. 153. 
antes: al formarse el artista una idea a partir de las acciones humanas particulares. Esto está validado por Aristóteles, puesto que él habla de que lo narrado por el poeta es universal y no particular. ${ }^{10} \mathrm{y}$, por lo tanto, no narra las acciones singulares sino una idea universal de la acción humana, posterior a la experimentación del particular $y$, como veíamos, superior a ella. La idea no copia la realidad, la mejora, en el sentido en que vuelve universal lo particular. Y la obra debe copiar la idea. Por ello, la obra puede ser considerada como verdadera si se asemeja a la idea original del artista sin que esto signifique que el artista deba copiar la realidad sin cambiarla.

Es necesario hablar de la veracidad de la metáfora, dado que es un elemento crucial en el estudio de cualquier arte poética. En la metáfora se funda la poesía, es el resultado de la reproducción imitativa, de la creatividad del artista y de la utilización de todas las técnicas poéticas. Recordamos que, según Aristóteles, la metáfora "es la transferencia del nombre de una cosa a otra"," y que esta transferencia se puede dar de varias maneras, que corresponden a los diversos tipos de metáfora: el primero, que transfiere el nombre del género hacia la especie; el segundo, que cambia el nombre de la especie por el del género; el tercero, que intercambia el nombre de una especie con el de otra que esté en el mismo género; y la cuarta, que procede por analogía.

El nombre es en la teoría aristotélica una voz significativa (semantikón) y no elucidativa (apofántikon). Esto es, que significa algo de la cosa referida pero que no la explica o define por completo. Esto da cabida a la existencia de la metáfora. Si el nombre fuera una voz elucidativa, un logos, una definición, no podría por ningún motivo cambiar de cosa referida. ${ }^{12}$

Respecto de la calificación veritativa que puede recibir cada tipo de metáfora podemos decir que, en el caso de la transferencia del

\footnotetext{
${ }^{10}$ Cf. Aristóteles: Poética, $1451 \mathrm{~b} 7$.

11 ARIsTóteles: Poética, $1457 \mathrm{~b} 8$.

12 La distancia existente entre la cosa y su nombre, adelantándonos a la comparación, es una idea que comparten Aristóteles y Octavio Paz.
} 
nombre del género a la especie, no hay, en rigor, falsedad. Si decimos, por ejemplo, que 'el perro es gris', y esto es verdadero, también será verdadero decir 'el animal es gris'. No obstante, este es el único tipo de metáfora que se salva de incurrir en una falsedad lógica. Cambiar el nombre de la especie por el del género, o por el de otra especie del mismo género, provocará siempre un enunciado falso. Pero debemos recordar que los enunciados de carácter poético, como son las metáforas, parecen estar exentas de una calificación lógica de verdad o falsedad. Por las razones expuestas con anterioridad acerca de los enunciados de la poesía, y dado que la metáfora es un enunciado poético, podemos aplicarle las mismas conclusiones que se hallan en párrafos anteriores.

Sobre el modelo eidético que funge como guía de la reproducción imitativa debemos decir que su origen, el origen de la idea del artista, se finca en última instancia en la experiencia. En efecto, la tragedia es una reproducción imitativa de la acción humana universalmente considerada bajo los criterios de necesidad y verosimilitud, pero para poder considerar universalmente una realidad, es necesario haber tenido experiencia de ella en tanto que particular, como se da en la realidad. Es por esta cuestión, que la idea puede ser verosímil, puesto que está fincada en ultima instancia en la realidad. La verosimilitud es necesaria para que el espectador, al presenciar la obra trágica, pueda tener los efectos catárticos que pretende el artista. Y si bien los enunciados poéticos no son susceptibles de verdad o de falsedad, si deben ser verosimiles, y esto se puede lograr gracias a que imitan acciones reales o, cuando menos, posibles.

\section{2. $\mathrm{Paz}$}

La postura de Octavio Paz respecto de la verdad de la poesía es un tanto distinta. Si bien está consciente de que la poesía problemáticamente alcanzaria un grado de verdad desde el punto de vista lógico, Paz hace énfasis en muchos pasajes de su obra en la importancia que la poesía tiene para el conocimiento. 
Paz piensa que puede haber un acercamiento antropológico a través de la poesía. Paz dice: "el acto poético, el poetizar, el decir del poeta - independientemente del contenido particular de ese decires un acto que no constituye, originalmente al menos, una interpretación, sinc una revelación de nuestra condición". ${ }^{13}$

Este hablarnos o revelarnos quiénes somoș, acto propio de la poesía, es un ponernos frente a nuestra propia verdad. En este sentido, aunque no estamos diciendo que la poesía diga verdad, sí podemos afirmar que nos coloca frente a una verdad antes velada: lo que somos realmente. Y sólo lo verdadero puede conducirnos a la verdad. En efecto, al ponernos frente a esta verdad de nuestro propio ser, parece que la poesía está preanunciando un abocamiento a conocer dicha verdad. La tarea del poeta y del hombre que se está valiendo de la poesía para descubrirse, será acercarse cognitivamente a la verdad que la poesia les ha revelado.

Al permitimos la poesia tener un acceso al propio ser, hablamos en efecto de un alcance cognitivo. El acceso permitido se da mediante el conocimiento de lo que la poesía nos revela. Este alcance cognoscitivo, autocognoscitivo, consiste en conocer quiénes somos en verdad. Si el conocimiento de nosotros mismos que brota del acto poético es un conocimiento verdadero, no podemos entonces poner en duda que la poesia nos dice verdades. No obstante, al afirmar esto no afirmamos que sólo diga verdades. Podemos decir, en otros términos, que la poesía, en tanto que nos da la clave interpretativa para conocernos de un modo que siempre habia estado velado para nosotros, nos dice verdades. Este es un primer sentido desde el que se puede defender la postura de que la poesia alcanza verdad. No debemos olvidar, no obstante, que hay varios registros desde los que podemos hablar de verdad. Esta verdad que se da en la experiencia del autoconocimiento, es sólo una de estas vertientes, que no ha sido claramente argumentada sino solamente expuesta desde un lenguaje menos riguroso, como lo hace $\mathrm{Paz}$.

\footnotetext{
${ }^{13}$ Octavio PAZ: El arco y la lira, México: F.C.E. 1972, p. 148. En adelante se citará con la abreviación $[\mathrm{AL}]$
} 
Por otra parte, la poesía es un modo de utilizar el lenguaje diferente a otros tantos modos de carácter más instrumental y menos de finalidad. Es la poesía, según Paz, el modo más perfecto de utilizar el lenguaje, dado que en el poema el lenguaje recobra su originalidad primera, mutilada por la reducción de significados que le han impuesto la prosa y el uso cotidiano del lenguaje. ${ }^{14} \mathrm{Y}$ esto no es casual, sino causal: en efecto, si todo lenguaje es, como dice Paz, un sistema expresivo dotado de poder significativo y comunicativo; y si además la poesía no cercena ningún posible significado de la palabra, sino que la deja en libertad; entonces, la poesia es lenguaje en mayor grado que otros sistemas, dado que tiene un poder más significativo que el lenguaje del habla cotidiana, por ejemplo, que reduce cada palabra a una única significación. La poesía es por estas razones un lenguaje utilizado en su modo más noble.

Ahora bien, si la finalidad del lenguaje es la de comunicar y significar, su uso más perfecto tendrá que comunicar y significar de un mejor modo. En efecto, la perfección de una realidad que es instrumental (en tanto que sirve para algo, en este caso, comunicar), debe calificarse en función de la mejor o peor consecución de su finalidad. Si Paz ha dicho que la poesía es el modo más perfecto de utilizar el lenguaje, entonces habrá advertido que es el modo en que más comunica y significa.

La verdad es comúnmente encontrada en el habla cotidiana y en los usos menos perfectos del lenguaje. Siendo la poesia el uso más perfecto y comunicativo, parece muy factible que comunique y signifique verdades. $Y$ aunque este no sea un argumento rigurosamente armado (nada que haga referencia a la poesía soporta un examen lógico o analítico), parece darnos la pauta para buscar la opinión de $\mathrm{Paz}$ al respecto.

Una condición de posibilidad para el conocimiento es, según Paz, el lenguaje. En efecto, "(...) no hay pensamiento sin lenguaje, ni tampoco objeto de conocimiento: lo primero que hace el hombre frente a una realidad desconocida es nombrarla, bautizarla. Lo que

${ }^{14}$ Cf. [AL] p. 22. 
ignoramos es lo innombrado". ${ }^{15}$ Por otra parte, al nombrar las cosas el nombre se convierte, en un sentido, en una metáfora de la cosa, pues la esencia del lenguaje es simbólica en tanto que consiste en representar un elemento de la realidad (la cosa) por otro (la palabra), según ocurre con las metáforas. Por tanto, la poesía, el lenguaje de las metáforas, es conocimiento. Nombra las cosas metafóricamente y las convierte en un verdadero objeto de conocimiento. La constante producción de imágenes que se nota en el lenguaje común, es una prueba del carácter simbolizante del lenguaje. "La poesía es lenguaje erguido" y "el lenguaje es poesía en estado natural". 16 Por tanto, la poesia debe ser un acto de conocimiento, dado que nombra las cosas y nombrarlas es una manera - la única, según $\mathrm{Paz}$ - de conocer la realidad.

Es necesario, antes de proseguir el análisis de las palabras de Paz en busca de una apología sobre la verdad poética, que distingamos algunas nociones que suelen confundirse porque guardan una relación estrecha entre ellas. Por una parte, la verdad es diferente a la verosimilitud; por otra, la verdad es diferente al sentido. Podemos decir que el sentido de una oración, es equivalente a lo que suele llamarse validez lógica. En efecto, la correcta construcción de una proposición, en la que deben participar sujeto y predicado y la afirmación o la negación de la unión entrambos, no tiene mucho que ver con la verdad de la proposición. Es cierto que para que una proposición pueda ser considerada como verdadera debe ser válida 0 , en otros términos, poseer sentido. Pero lo falso puede tener sentido, en tanto que sea una proposición o un juicio dotado de corrección pero que exprese algo que no concuerde con la realidad tal cual es. La poesía, a su vez, debe tener sentido, independientemente de la verdad o de la falsedad que lleve en sus entrañas. Todo parece indicarnos que el sentido es algo así como el no salirse de las reglas previamente aceptadas para la expresión de una realidad o una irrealidad. Sea para la lógica el conjunto de axiomas del conocimiento y para el poema y la tragedia los axiomas internos a cada obra. Por ejemplo, en una tragedia griega se ha aceptado la

${ }^{15}$ [AL] p. 30.

${ }^{16}[\mathrm{AL}]$ p. 34. 
postulación de la existencia real de los dioses que intervienen en ella. Con independencia de la verdad o de la falsedad que genere la proposición "los dioses existen realmente", al aceptarla desde el inicio de la tragedia, la aparición de los dioses en la tragedia tiene sentido.

Ahora bien, es importante mostrar que lo falso puede tener sentido, pero que lo verdadero ha de tenerlo necesariamente. El sinsentido no puede ser verdadero. Lo inverosímil, por otra parte, carece de verdad y de sentido, por lo que no es siquiera creible. Si la poesía ha de ser verosimil, por tanto, debe tener al menos sentido. $\mathrm{Y}$ para poder aspirar a la verdad, la poesía debe tener sentido, puesto que el sentido es una condición de posibilidad para lograr decir verdad. Es esta la razón por la que la poesía debe tener sentido, puesto que tanto para Paz como para Aristóteles, la poesía se mueve al menos en el campo de lo verosímil.

En estos momentos, debemos dar por sentado que la poesía tiene, al menos, sentido, aun cuando no hallamos desentrañado si dice verdad o no. De lo contrario, todo este examen habría sido realizado en balde. A continuación, acudiremos a las palabras de Octavio Paz que desacreditan la tesis de que la poesía dice verdad, con ocasión de realizar un examen exhaustivo del tema y no concluir parcialidades.

La poesía, como hemos visto utiliza como elemento a la imagen. La imagen es una forma verbal, una frase o un conjunto de frases que integra al poema. ${ }^{17} \mathrm{La}$ imagen tiene como característica principal el preservar todos los posibles significados de las palabras que la componen, sin atentar contra esta pluralidad significativa es que deja a la palabra en un estado más libre y más perfecto. No obstante, cada imagen o cada poema tiene muchos significados no sólo dispares, sino que aun son contrarios o contradictorios. La imagen abarca todos estos significados y los concilia sin suprimirlos. "El poeta nombra las cosas: éstas son plumas, aquéllas son piedras. Y de pronto afirma: las piedras son plumas, esto es aquello". ${ }^{8} \mathrm{Y}$ al

${ }^{17} \mathrm{Cf} .[\mathrm{AL}]$ p. 98.

18 [AL] p. 99. 
enunciar la identidad de los contrarios atenta contra los fundamentos del pensar, atenta contra el axioma más originario del pensar humano: el principio de no contradicción.

Este atentar contra el principio más originario de nuestro pensar pone en problemas la concepción de la poesía como un acto que genera o expresa verdades. En efecto, dice $\mathrm{Paz}$ que es por esto que "la realidad poética de la imagen no puede aspirar a la verdad. El poema no dice lo que es, sino lo que podría ser. Su reino no es el del ser, sino el del 'imposible verosímil' de Aristóteles". 19

La verdad a la que Paz se está refiriendo cuando la aleja por completo de la poesia es, sin duda, la verdad lógica. Un poco más adelante, en la misma obra, Paz hará una rápida revisión a las posturas occidentales acerca de los contrarios y su compatibilidad. En concreto, habla del ser y del no-ser, como fundamento último de todo par de contrarios. Se hace un recuento que arranca con Parménides y que concluye con los esfuerzos hegelianos de retomar la doctrina heracliteana.

Sin embargo, la respuesta que parece satisfacer más la necesidad de Paz en tanto que poeta, esto es, la de mantener alto el valor de la poesía como acceso a la verdad, se inclina hacia el mundo oriental: "El pensamiento oriental no ha padecido este horror hacia lo 'otro', a lo que es y no es al mismo tiempo. El mundo occidental es el del 'esto o aquello'; el oriental, el del 'esto y aquello' y aun el de 'esto es aquello".20

La lógica convencional no podrá avalar el alcance cognoscitivo o veritativo de la poesia. La lógica convencional es un elemento surgido de la tradición occidental, de la tradición que parte de la división unívoca parmenídea del ser y el no-ser, que no da lugar sino a una sola significación. Para entrever la posible verdad que comunica la poesía, Paz tiene que acudir a la tradición oriental, que tanto le impresionó, y salirse de los esquemas mentales occidentales,

${ }^{19}[\mathrm{AL}]$ p. 99.

20 [AL] p. 102. 
que dificultan la concepción de una índole de verdad fuera de la de carácter lógico: "El conocimiento que nos proponen las doctrinas orientales no es transmisible en fórmulas o razonamientos. La verdad es una experiencia y cada uno debe intentarla por su cuenta y riesgo". ${ }^{21}$

La verdad está siendo concebida por Paz bajo un aspecto menos científico - como lo es el lógico- y más vivencial. Al hacer antropología por método poético, al conocernos a nosotros mismos a través de la poesía, se está experimentando una verdad vivida y no pensada. La imagen descubre quienes somos, nos lo muestra como se da una intuición, no después de un despliegue discursivo de nuestro entendimiento. La verdad, en el plano de la presentación y la representación, en el plano de lo que se intuye y de lo que se vive, no es idéntica a la verdad desde el plano lógico. En éste último, no se admite la múltiple significación, la unión de los contrarios, ni la creación de imágenes poéticas, características las tres del obrar poético.

Ante esta carencia de verdad desde el ámbito del pensamiento discursivo, ante esta negación flagrante del principio de no contradicción, Paz advierte que la poesia alcanza verdad dentro de su propia esfera. Pero esta verdad no se puede reducir a la noción de sentido. No obstante, la imagen, a pesar de que varios y dispares significados luchan en su interior, posee sentido. Esto por dos razones: primero, la imagen posee autenticidad, el poeta la ha visto o escuchado, es la expresión genuina de su visión y experiencia; segundo, la imagen constituye una realidad objetiva, válida por sí misma, es una obra. ${ }^{22}$

Y deciamos que además de sentido, la imagen alcanza verdad:

(...) el poeta hace algo más que decir la verdad; crea realidades dueñas de una verdad: las de su propia existencia. Las imágenes poéticas poseen su propia lógica y nadie se

\footnotetext{
${ }^{21}$ [AL] p. 103.

22 Cf. $[\mathrm{AL}]$ p. 107.
} 
escandaliza porque el poeta diga que el agua es cristal o que el 'pirú es primo del sauce' (Carlos Pellicer). Mas esta verdad estética de la imagen vale dentro de su propio universo. Finalmente, el poeta afirma que sus imágenes nos dicen algo sobre el mundo y sobre nosotros mismos y que ese algo, aunque parezca disparatado, nos revela de veras lo que somos. ${ }^{23}$

Como vemos, las imágenes de las que se vale el poeta tienen una verdad propia, en tanto que existen como imágenes y, en último término, en tanto que nos hablan de una experiencia real, la del poeta. Y así, la teoría de Paz acerca de la imagen poética termina acercándose de manera absoluta a las teorías típicas de la percepción sensorial. "El poeta no describe la silla, nos la pone en frente". ${ }^{24}$ Análogamente al momento de la percepción, la imagen poética nos coloca la realidad con todas sus contrarias cualidades. La imagen reproduce el momento de la percepción. La imagen no representa, sino presenta.

Dadas todas estas consecuencias extraidas directamente de las palabras de Paz sobre el asunto, podemos decir que la poesía, por una parte, está condenada a permanecer ajena al círculo de la verdad. Esto porque niega el principio de no contradicción y pronuncia falsedades desde un punto de vista analítico o lógico. Pero por otra parte, la poesía nos dice verdad desde un punto de vista más vivencial, análogo al proceder de la percepción sensorial. Y esta verdad es una verdad inherente a la obra artistica, como lo hemos constatado unas líneas arriba.

La transmisión de esta verdad resulta, sin embargo, complicada. Y esto se debe a las dificultades que encuentra el mismo lenguaje para hacerse escuchar cuando se trata de comunicar experiencias. La subjetividad ronda la obra de Paz cuando se tratan estos temas, la aparente imposibilidad para salir de la propia percepción se repite en el intento por comunicar verdades vivenciales, propias de la poesía.

${ }^{23}[\mathrm{AL}]$ pp. 107 y 108.

${ }^{24}$ [AL] p. 109. 
Por supuesto, la manera propia de la comunicación de la imagen no es la transmisión conceptual. ${ }^{25}$

Podemos decir, para culminar este apartado, que

la verdad del poema se apoya en la experiencia poética, que no difiere esencialmente de la experiencia de identificación con la 'realidad de la realidad', tal como ha sido descrita por el pensamiento oriental y parte del occidental. Esta experiencia, reputada por indecible, se expresa y comunica en la imagen. ${ }^{26}$

\section{Semejanzas y diferencias entre ambos autores}

Es necesario, antes de proceder a la comparación y para hacerla correctamente, señalar que los autores que se tratan en este trabajo tienen un contexto completamente distinto uno del otro. En primer lugar, Aristóteles es un filósofo que está haciendo una teoría sobre la correcta creación del arte de la poesía. Paz, en cambio, es un poeta, situado en un momento histórico antagónicamente diferente al del primero, y que pretende, con su obra, hacer una especie de apología o defensa de la poesía, del proceder poético y del valor intrínseco que puede tener este arte. El Arco y la Lira constituye una defensa de la plena significación, del poder y de la irreductibilidad del acto poético. ${ }^{27}$ Ambos textos comparten un mismo tema, es cierto, pero se despegan considerablemente en el modo en que se abordan $y$, por lo tanto, también en la finalidad que persiguen.

Ambos están de acuerdo en que la poesía no puede aspirar a la verdad desde el punto de vista lógico. Aristóteles nos dice que los juicios o sentencias que atañen a la poesía no son siquiera susceptibles de ser calificados como verdaderos o falsos ${ }^{28}$, seguramente apoyado en la tesis de que, al no ser descriptivos de la

${ }^{25} \mathrm{Cf} .[\mathrm{AL}]$ p. 113.

26 [AL] p. 112

27 Cf. Enrico Mario Santi: El Acto de las Palabras. Estudios y Diálogos con Octavio Paz. México: F.C.E. 1997, p. 238.

${ }^{28} \mathrm{Ct}$. Peri Hermeneias, 17 a 1-8. 
realidad, no es posible compararlos con ella para encontrar su valor veritativo. Ambos han advertido - quizá por ser una típica crítica contra la poesía- que la poesía no es un lenguaje común, y que no puede ser calificado como tal porque no procede comúnmente. En efecto, la poesia no dice verdades lógicas, pero esto no es necesariamente un defecto. No dice verdades lógicas porque, en el caso de Aristóteles, sus enunciados no son de tal modo que puedan ser analizados por la lógica, son de otra índole y por eso escapan al examen analítico de comparación con la realidad. En el caso de Paz, porque la poesía utiliza imágenes, que no llegan a ser juicios y que, por tanto, no representan alguna característica, sino que la presentan. Asemejando el acto de la creación de imágenes poéticas al acto de la percepción, ambos se encuentran en un nivel en el que no se ha enjuiciado nada y en el que, por tanto, no se dice algo verdadero o falso sobre alguna realidad.

Otro punto en que están de acuerdo será el de la verdad ontológica. Si bien no utilizan esta nomenclatura, ambos aceptan que la obra artística tiene un valor propio por el sólo hecho de existir, con independencia de lo que digan, muestren o afirmen. La obra existe en la realidad como tal y es, pues, verdadera en tanto que existente. Aristóteles dice que la verdad lógica no está en las cosas, sino en el pensamiento, ${ }^{29}$ diferenciando esta verdad a la de la mera presencia o existencia de las cosas. Paz nos dice que la imagen poética constituye una realidad objetiva, válida por sí misma porque es una obra. $^{30}$

En cuanto lo referente a la verdad poética, parecen coincidir ambos autores, al menos, en que la poesía no alcanza una verdad de tipo lógico, aunque sí poseen una verdad ontológica en el sentido en que existen como obras. No obstante, Aristóteles está consciente de que la obra, en cuanto tal, es resultado de una reproducción imitativa, lo cual le confiere menos entidad, por decirlo así, que la que tiene el modelo del cual copia. Es cierto también que la tragedia se ocupa de reproducir acciones pero de un modo universal, y dado que las

${ }^{29}$ Cf. ARISTóteles: Metafisica, 1027b 25-27.

${ }^{30} \mathrm{Cf}$. [AL] p. 107. 
acciones siempre son particulares, habiamos concluido que la imitación utiliza como modelo una idea, que está entresacada de la experiencia de acciones particulares, pero llevada hasta la universalización. Habría cabida, pues, a una cierta verdad lógica que sea fruto de la comparación, aunque en este caso la comparación se daría entre la idea modelo y la obra resultante. Así, de ser concordantes, habrá cierta verdad entendida como adecuación. Paz piensa que, por una parte, este es el modo de proceder de la poesía, y por otro, que es el modo que Aristóteles acepta como cierto. ${ }^{31}$

Vimos que el sentido no es lo mismo que la verdad, pero que sí es una condición de posibilidad para poder comunicar verdades. En efecto, todo lo verdadero tiene sentido aunque no todo lo que tiene sentido sea verdadero. Ahora bien, la noción más importante en que estos autores coinciden es la de verosimilitud. Tanto Paz como Aristóteles están de acuerdo en que la poesía habla de cosas verosímiles:

De Aristóteles: "resulta claro no ser oficio del poeta el contar las cosas tal y como sucedieron, sino cual deseariamos hubieran sucedido, y tratar lo posible según verosimilitud o según necesidad". ${ }^{32}$ El campo de acción de la poesía es el de lo posible, y como hemos visto esta 'posibilidad' es la que permite que la poesia, aunque narre acciones - que son naturalmente singulares- pueda hablar sobre universales.

De Paz: "la realidad poética de la imagen no puede aspirar a la verdad. El poema no dice lo que es, sino lo que podría ser. Su reino no es el del ser, sino el del 'imposible verosimil' de Aristóteles". ${ }^{33}$ La poesia, pues, también según Paz e incluso citando a Aristóteles, se mueve en el campo de lo que podría ser, de la posibilidad. Ciertamente resulta extraño por qué Paz se refiere al verosímil como 'imposible', sea quizá porque el tema de la poesía aristotélica es la acción universal, que es imposible en el dominio de lo fáctico.

\footnotetext{
${ }^{31} \mathrm{Cf}$. [AL] pp. 66 y 67

32 ARIstóteles: Poética 1451a 36-38.

${ }^{33}$ [AL] p. 99.
} 
Ya hemos esbozado una primera conclusión con respecto al análisis de las coincidencias entre ambos autores. La poesía debe ser verosímil. El matiz que cada uno aporta es, sin embargo, muy diferente. Aristóteles habla de que las acciones narradas sean posibles o creíbles. Paz señala que la imagen poética ha de ser verosimil, y esto quizá fincado en que la imagen surge de una experiencia real del poeta: él ha vịsto las imágenes que expresa. En ello puede fincarse la verosimilitud de la imagen.

$Y$ en efecto, si un poeta afirmase que el agua es cristal, lo hace debido a que presenció experimentalmente al agua como si fuese un cristal. No está mintiendo dado que expresa una imagen sin enjuiciarla y esa imagen ha sido vista por él. El poeta no tiene los mismos ojos que el hombre común ni que el científico. Paz no es un filósofo, es un poeta.

¿Cómo aspira la poesía a una verdad y de qué índole es ésta? Concluyamos el análisis. Primeramente, Aristóteles acepta la verdad de la obra artística en tanto que existente. Además, acercá la poesía - más que la historia - a la labor filosófica, cuya finalidad es la verdad. Además, aceptaría que la poesía bien hecha aspire a conseguir otra verdad: la de adecuación entre la obra y la idea del artista que sirve como modelo para su actuar. Una idea fruto de la percepción experimental de la acción humana y de su nobleza. Por último, dado que la poesía es verosímil y esto puede lograr en el espectador algunos efectos con la intención de realizar una catarsis, la poesía puede considerarse verdadera en tanto que causa un efecto real. Esto último sea quizá un elemento clave para poder entender que la poesía sea verdadera.

Posteriormente, Paz otorga una verdad de indole diversa a la poesía. Si bien está de acuerdo en la verdad ontológica de la obra en tanto que real, también aceptará otros ámbitos en que la poesía es verdadera. En primer lugar, en cuanto que nos habla de nosotros mismos y es un modo fehaciente para descubrir aquello de nosotros que permanecía oculto antes de acudir a la poesia. Además, en tanto que el lenguaje en general comunica verdades y la poesía es el lenguaje utilizado en su forma más perfecta. Esto es, en tanto que la 
poesía comunica verdades, es verdadera. Y más importante, la poesía "hace más que decir la verdad, crea realidades dueñas de su propia verdad". Es una "verdad estética de la imagen", 34 una real belleza que se encuentra en la imagen poética, a fin de cuentas, una verdad. Por último, la poesía nos dice verdad desde un punto de vista vivencial, procediendo análogamente que la percepción.

Es innegable la trascendencia de ambos autores, la coincidencia en los términos generales de sus opiniones acerca de estos temas no es casual. Paz conocia a Aristóteles, y aunque no utiliza los mismos argumentos, parece, en fin, estar muy cerca de su postura. Podemos decir que una comparación entre ellos no es sino una acumulación de argumentos a favor de la consideración verosimil o verdadera de la poesía desde el punto de vista de la investigación intelectual. Si no están escritos a manera de apología de la poesía, si pueden ser utilizados como tal sus escritos acerca del tema. 
Copyright of Tópicos. Revista de Filosofía is the property of Universidad Panamericana and its content may not be copied or emailed to multiple sites or posted to a listserv without the copyright holder's express written permission. However, users may print, download, or email articles for individual use. 